\title{
Acetaminophen Changes Intestinal Epithelial Cell Membrane Properties, Subsequently Affecting Absorption Processes
}

\author{
Christine Schäfer ${ }^{a}$ Klaus Rudolf Schröder ${ }^{a}$ Otmar Höglinger ${ }^{b}$ Sajjad Tollabimazraehnoc,d \\ Mohammad Reza Lornejad-Schäfera \\ aBioMed-zet Life Science GmbH, Linz, Austria; 'bSchool of Engineering/Environmental Sciences, Upper \\ Austria University of Applied Sciences, Wels, Austria; ' $C e n t e r$ for Surface and Nanoanalytics (ZONA), \\ Johannes Kepler University (JKU), Linz, Austria; ${ }^{\mathrm{d} D e p a r t m e n t ~ o f ~ P h y s i c s, ~ U n i v e r s i t y ~ o f ~ C a l i f o r n i a ~ a t ~}$ \\ Berkeley, Berkeley, California 94720, United States
}

\section{Key Words}

Acetaminophen $\bullet$ Intestinal barrier model $\bullet$ Membrane properties $\bullet$ Impedance $・$ Microvilli

\begin{abstract}
Background/Aims: Acetaminophen (APAP) effects on intestinal barrier properties are less investigated. APAP may lead to a changed bioavailability of a subsequently administered drug or diet in the body. We investigated the influence of APAP on enterocytic cell membrane properties that are able to modify the net intestinal absorption of administered substances across the Caco-2 barrier model. Methods: The effect of APAP on cytotoxicity was measured by LDH assay, TER value and cell capacitance label-free using impedance monitoring, membrane permeability by FITC-dextrans, and efflux transporter MDR1 activity by Rh123. APAP levels were determined by HPLC analysis. Cell membrane topography and microvilli were investigated using SEM and intestinal alkaline phosphatase (Alpi) and tight junction protein 1 (TJP1) expression by western blot analysis. Results: APAP changed the apical cell surface, reduced the number of microvilli and protein expression of Alpi as a brush border marker and TJP1, increased the membrane integrity and concurrently decreased cell capacitance over time. In addition, APAP decreased the permeability to small molecules and increased the efflux transporter activity, MDR1. Conclusion: APAP alters the Caco-2 cell membrane properties by different mechanisms and reduces the permeability to administered substances. These findings may help to optimize therapeutic implications.
\end{abstract}




\section{Introduction}

Acetaminophen (APAP) or paracetamol ( $\mathrm{N}$-acetyl-p-aminophenol) is considered a safe and effective drug against pain and fever for use at therapeutic doses (1g per single dose and up to $4 \mathrm{~g}$ per day for adults) $[1,2]$. There are about 600 products that contain APAP, like cough and cold products and sleep aids. APAP is also an ingredient in many pain relievers. For instance, APAP is used in post-surgical pain treatment, palliative care and osteoarthritis treatment. It is well known that acute overdoses of APAP can cause liver damage [3]. APAP toxicity is dose-dependent and results from one of its metabolites, N-acetyl-pbenzoquinoneimine (NAPQI) that depletes the natural antioxidant glutathione and directly damages cells, mainly in the liver, leading to liver failure or other undesired side effect [3]. In therapeutic dose, APAP has not been found to be associated with increased gastro-intestinal toxicity [4-7].

After ingestion, the neutral and low hydrophilic small molecule APAP is rapidly and completely absorbed within minutes until few hours. Absorption from the intestine occurs passively by diffusion through trans- and paracellular pathways [8]. APAP is therefore an ideal candidate for the study of adaptive changes on intestinal barrier properties [9]. APAP plasma half-life is about $4 \mathrm{~h}$, longer half-lives reflect a greater toxic effect on the liver [10]. However, therapeutic and supratherapeutic doses of APAP given orally could also affect the intestine. APAP efficacy may be altered by another substance like a subsequently administered drug or nutrient. In addition, understanding the intestinal changes and identifying new APAP side effects could improve treatment of patients who used APAP in a suicide attempt [1], or who accidentally overdosed on APAP to relieve severe pain after surgery [11].

The intestine is the first barrier for the intake of APAP and therefore we suggested its regulatory function during absorption of this drug. There is clinical evidence that humans, like rodents, can adapt to APAP-induced toxicity, which supports preclinical evaluation of the mechanism underlying APAP autoprotection [12-14]. It has not yet been investigated whether APAP affects the intestinal cell membrane properties and modulates the net intestinal absorption of itself or other substances present in the lumen. The extent of intestinal absorption - the net intestinal absorption - is a result of chemical properties of the substance, passive permeation properties, carrier-mediated transport, active uptake and efflux systems, and intestinal metabolic enzymes $[15,16]$. Important structural components of the intestinal barrier are the lateral adhesions complexes and microvilli. Tight junctions are the most apically located lateral adhesion complexes between polarized enterocytes that separate the apical (luminal) region from the intercellular space. Tight junctions limit transport via this paracellular route to small polar or hydrophilic molecules. Substances with high membrane permeability like lipophilic molecules are able to pass transcellularly [17].

Visualization of the cell surface using Atom force microscopy (AFM) analysis shows that APAP changes the cell topography of differentiated Caco- 2 cells [18]. Here, we investigate the effect of APAP on the intestinal microvilli for the first time. Microvilli organized in the brush border are apical protrusions which enlarge the absorptive and secretory apical cell surface area of the intestinal epithelial cells [19]. Recently, their fundamental role in the functions of differentiated polarized cells has been recognized as an universal regulation and defence system at the cell periphery. The defence against cytotoxic compounds may be one of their functions [20]. One typical intestinal brush border marker protein is the intestinal alkaline phosphatase (Alpi). In vivo, Alpi is located at the interface between the intestinal tissue, the ingesta and the vast microbiota, suggesting involvement in a variety of biological processes [21]. Furthermore, intestinal absorption can be limited by efflux transporters like the ATP-dependent efflux transporter P-glycoprotein 1 (Pgp1), which is also known as multi drug resistance protein 1 (MDR1) or ATP-binding cassette, sub-family B, member 1 (ABCB1). Increased intestinal expression of Pgp1 has been shown to reduce the absorption of drugs that are substrates for Pgp1. MDR1 is also responsible for multiple drug resistance in tumour cells [22]. 
We address APAP related alterations in membrane properties using the Caco-2 barrier model which is one of most frequently used and best established in vitro models for determining drug permeability across intestinal membranes [23]. In this study, we investigate the influence of APAP on the expression of Alpi, on cell surface and on the number of microvilli through ultrastructure analysis. To monitor the effect of APAP on the barrier function, we use impedance spectroscopy, a label-free, non-invasive method followed by transporter assays in order to find out, 1) whether physical membrane properties like membrane integrity and cell capacitance may be changed, 2) whether MDR1 transporter is regulated by APAP, and 3) whether APAP retreatment can change the permeability of administered substances to APAP and to other small molecules.

\section{Materials and Methods}

\section{Materials}

Materials for cell culture were obtained from Greiner Bio-one (Austria) and Nunc GmbH \& Co. KG (Thermo scientific, Austria), cell culture media, supplements and antibodies from Sigma-Aldrich (Austria) and Lonza (Belgium). All other chemicals were purchased from Sigma-Aldrich (Austria).

\section{Caco-2 cell culture}

Caco-2 cells are derived from human colorectal adenocarcinoma and form monolayers (like human intestinal epithelium) under conventional culture conditions and have been widely used as a potent invitro model to predict drug absorption in humans and to explore mechanisms of drug absorption [24, 25]. Caco-2 cells were purchased from DSMZ (Germany) and maintained in DMEM medium ( $4.5 \mathrm{~g}$ glucose/l), with $20 \%$ FCS, 1\% Pen/Strep, 1 x MEM NON-Essential Amino Acid + 10 mM Hepes and pH 7.4. Caco-2 cells between passages 51-76 were used. To reconstruct a functional intestinal cell barrier model, 120.000 Caco2 cells/well $\left(=200.000\right.$ cells $\left./ \mathrm{cm}^{2}\right)$ were seeded onto polycarbonate hanging cell culture inserts with a 0.4 $\mu \mathrm{M}$ pore size on an area of $0.7 \mathrm{~cm}^{2}$ (24-Well Millicell, Millipore, Germany) for 21 days. Cell culture medium was changed every 2 to 3 days. To study the effect of APAP on the Caco-2 cell barrier model, cells were treated with APAP or a vehicle (DMSO) for $24 \mathrm{~h}$.

\section{TER measurement}

Transepithelial electrical resistance (TER) measurement is a method used to assess the integrity of Caco-2 cell monolayers [26]. The Millicell ERS-2 (Electrical Resistance System) (Millipore, Germany) which was used is a Volt-Ohm meter and electrode system designed to measure the TER of epithelial cells in a culture. The standard TER values of 21 days differentiated. Caco- 2 cells were between 250 and $330 \mathrm{Ohm} \mathrm{x}$ $\mathrm{cm}^{2}$ at $37^{\circ} \mathrm{C}$.

An increase in TER (detected with the electronic circuit of the Millicell ERS-2 meter and its electrode) is an indication of the monolayer's health and the cell's confluence with barrier properties. The TER value was measured prior to and after $24 \mathrm{~h}$ incubation time with DMSO (vehicle) and APAP.

\section{Impedance monitoring}

Using automated cell monitoring systems continuous data recording while the cell cultures remain in the incubator is possible. TER and cell capacitance (Ccl) can be measured simultaneously in real time and non-invasively. Using the cellZsope ${ }^{\circledR}$ system (nanoAnalytics, Germany), the TER $\left(\mathrm{Ohm} \mathrm{x} \mathrm{cm}{ }^{2}\right)$ and cell capacitance ( $\mathrm{Ccl}$ ) of the Caco-2 barrier model were continuously measured prior to, during and after treatment with vehicle (DMSO) and APAP. The baseline TER values were around $230-260 \mathrm{Ohm} \mathrm{x} \mathrm{cm}{ }^{2}$ before APAP or the corresponding vehicle (DMSO) addition.

\section{Determination of cytotoxicity by Lactate Dehydrogenase (LDH) assay}

Lactate dehydrogenase (LDH) is an oxidoreductase which catalyses the interconversion of lactate and pyruvate. LDH can be measured to assess the presence of tissue or cell damage. The release of LDH from cells into the medium was measured spectrophotometrically using the LDH cytotoxicity detection kit 
(Roche Diagnostics, Germany) according to the manufacturer's protocol. Supernatants from cell culture samples were collected $24 \mathrm{~h}$ after APAP treatment.

Measurement of mitochondrial membrane potential $(\Delta \Psi \mathrm{Ym})$ by JC-1 assay

The JC-1 assay kit (Sigma Aldrich, Austria) uses the fluorescent cationic dye JC-1 (5,5',6,6'-tetrachloro$1,1^{\prime}, 3,3^{\prime}$-tetraethylbenzimi-dazolylcarbocyanine iodide) to signal the loss of mitochondrial membrane potential $\Delta \Psi \mathrm{m}$ [27]. In viable cells, JC-1 is a monomer in the cytosol and stains green, but accumulates in intact mitochondria with high mitochondrial membrane potential and forms aggregates, which stain red. When mitochondrial membrane potential breakdown occurs, JC-1 cannot accumulate and form aggregates in mitochondria. The decrease in red fluorescence counts indicates the decrease in aggregates, mitochondrial membrane potential depolarization and cell damage [27]. After incubation with APAP, the Caco-2 cells were washed with PBS, trypsinized, and stained with JC-1 dye in culture medium. After 20 min incubation time at $37^{\circ} \mathrm{C}$ with $5 \% \mathrm{CO}_{2^{\prime}}$, the cells were washed with cold PBS and fluorescence was determined using a fluorescence plate reader (Infinite M200 Tecan, Austria) with appropriate filter sets. The aggregate red form has absorption/emission maxima of 525/590 $\mathrm{nm}$. The green monomeric form has absorption/ emission maxima of 490/530 $\mathrm{nm}$. The ratio of red fluorescence divided by green fluorescence was calculated. The ratio of red to green fluorescence is decreased in dead cells and in cells undergoing apoptosis compared to healthy cells. Valinomycin treated cells were used as positive control.

\section{Measurement of membrane permeability using different sized FITC-dextrans}

Drug permeability studies were performed according to Hubatsch et al. [25]. Fluorescein isothiocyanate (FITC)-dextran is supplied as a yellow/orange powder which dissolves freely in water or salt solutions and makes a yellow solution (Sigma-Aldrich, Austria). FITC-dextrans are primarily used for studying permeability and transport in cells and tissues. To test the selective permeability of our Caco2 barrier model, the differentiated Caco- 2 cells were incubated with $1 \mathrm{mg} / \mathrm{ml}$ FITC-dextrans of different molecular masses: small FITC-dextran (3-5 kDa) and large FITC-dextran (40 kDa) within the transport buffer (DMEM medium without phenol red, $2 \mathrm{mM}$ L-Glutamine, $10 \mathrm{mM}$ Hepes buffer pH7.4. Aliquots were withdrawn from the lower chambers and the fluorescence intensity of the FITC-dextran was measured using the fluorescence microplate reader Infinite M200 (Tecan, Austria), with excitation at $490 \mathrm{~nm}$ and emission at $520 \mathrm{~nm}$ after $24 \mathrm{~h}$ or/and $48 \mathrm{~h}$ incubation time.

\section{Cell surface and microvilli investigation by SEM}

Scanning electron microscope (SEM) analysis is a technique for investigating tissue surfaces at high resolution. Using the SEM (Carl Zeiss 1540 XB, Germany), the surface of the Caco-2 barrier model prior to and after treatment with DMSO (vehicle) and APAP was studied. After treatment, the cells were washed twice with PBS (phosphate buffer, $\mathrm{pH}$ 7.5) and chemically fixed using Karnovsky solution $(6.25 \%$ glutaraldehyde and $6.25 \%$ paraformaldehyd in phosphate buffer, $\mathrm{pH} 7.5$ ) over night at $4^{\circ} \mathrm{C}$. Then all samples were dehydrated in ethanol (50-100\%). Dried samples were fixed on Al SEM sample holders using doublesided sticky carbon tape. A gold layer was placed over the tissue surface with a thickness of $5 \mathrm{~nm}$ by DC across the system (HAMMER X, Germany). Cell surface and microvilli were examined by SEM (Carl Zeiss $1540 \mathrm{XB}$, Germany). For the sake of getting best imaging conditions, 3 and $5 \mathrm{KV}$ acceleration voltages and 3 and $5 \mathrm{~mm}$ working distances were chosen at different magnifications.

\section{Measurement of MDR1 activity using Rhodamine 123 (Rh123)}

$\mathrm{Rh} 123$ is a cell-permeant, cationic, green-fluorescent dye that is readily sequestered by active mitochondria without cytotoxic effects. Rh123 is a substrate for the MDR1 transporter [28, 29]. To test the effect of APAP on the MDR1 activity, the differentiated Caco-2 cells were preincubated with different concentrations of DMSO (vehicle) or/and APAP on the apical side followed by further incubation with $5 \mu \mathrm{g} /$ $\mathrm{ml}$ Rh123 on the basolateral side within transport buffer (DMEM medium with $4.5 \mathrm{~g}$ glucose/l), without phenol red, $2 \mathrm{mM} \mathrm{L-glutamine,} \mathrm{and} 10 \mathrm{mM}$ Hepes buffer pH7.4 for $24 \mathrm{~h}$. The fluorescence intensity of Rh123 was measured using the fluorescence microplate reader Infinite M200 (Tecan, Austria) with excitation at $485 \mathrm{~nm}$ and emission at $535 \mathrm{~nm}$. 


\section{Measurement of APAP by HPLC analysis}

The HPLC system consisted of a JASCO 2000+ Series high performance liquid chromatograph equipped with autosampler, diode array detector, column oven and quaternary pump (Jasco Inc., Japan). The Software Chrompass V1.74 (Jasco Inc., Japan) was used to integrate and calculate the separated peak areas. Calibration was performed with the method of external standard. After $24 \mathrm{~h}$ incubation with APAP, $100 \mu \mathrm{l}$ of cell culture media was taken. Aliquots were centrifuged for $5 \mathrm{~min}$ at $13.200 \mathrm{rpm}$ and diluted with 1 part of the sample to 19 parts of water. $20 \mu \mathrm{l}$ of this mix was then injected into the HPLC system (Jasco Inc., Japan). An Interchrom Devosil $525 \mathrm{QK}$ C18 column $(250 \times 4.6 \mathrm{~mm}, 5 \mu \mathrm{m})$, tempered at $30^{\circ} \mathrm{C}$, was used for isocratic chromatographic separation (Interchim, France). The mobile phase was $4.5 \%$ Acetonitrile, and flow rates were set at $1 \mathrm{ml} / \mathrm{min}$. UV detection was monitored at $250 \mathrm{~nm}$ wavelength.

\section{Preparation of Triton-soluble and Triton-insoluble fractions}

Preparation of Triton-soluble and Triton-insoluble fractions was performed with some modification according to the method described by Seth et al. [30]. After treatment with APAP and its vehicle, cells were washed one time with an ice-cold phosphate buffer, $\mathrm{pH}$ 7.4. Cells were harvested from four inserts of a 24-well culture plate and the proteins were extracted in $750 \mu$ lysis buffer CS (50 mM Tris- $\mathrm{HCl}, 1 \%$ Triton $\mathrm{X}-100,1 \mathrm{mM} \mathrm{Na}_{3} \mathrm{VO}_{4}, 1 \mathrm{mM}$ PMSF, and a protease inhibitors cocktail tablet). Extracts were centrifugated at $13000 \mathrm{rpm}(=24562 \mathrm{~g}), 10 \mathrm{~min}$ at $4^{\circ} \mathrm{C}$ and the pellet (Triton-insoluble fractions) was suspended in $250 \mu \mathrm{l}$ of lysis buffer N ( $20 \mathrm{mM}$ Tris- $\mathrm{HCl}, 0.2 \%$ Nonidet P- $40,0.2 \%$ Na-deoxycholate, and a protease inhibitor cocktail tablet) (Sigma Aldrich, Austria). Extracts were then incubated on ice for $15 \mathrm{~min}$. After that, the suspension of the pellets was sonicated for 10 seconds and centrifugated at low speed $(1000 \mathrm{rpm}=145 \mathrm{~g})$ for $10 \mathrm{~min}$ at $4^{\circ} \mathrm{C}$.

\section{Immunoprecipitation}

For immunoprecipitation, $75 \mu \mathrm{l}$ of Triton-soluble and $25 \mu \mathrm{l}$ Triton-insoluble fractions were incubated over night at $4^{\circ} \mathrm{C}$ with $2 \mu \mathrm{g}$ monoclonal antibody. To capture the immunocomplex, $100 \mu \mathrm{l}$ protein- $\mathrm{A}$ sepharose was added, and the fractions were incubated with slow end-over-end mixing for at least $2 \mathrm{~h}$ at room temperature. After that, the sepharose beads were collected by pulse centrifugation (30 seconds, $1300 \mathrm{rpm}=246 \mathrm{~g}$ ) and the supernatant was discarded. Collected sepharose was washed two times with binding buffer, resuspended in $35 \mu \mathrm{l}$ of $2 \times$ Laemmli's sample buffer, and heated at $90^{\circ} \mathrm{C}$ for $5 \mathrm{~min}$. After that, immunoprecipitates were analysed for the TJP1 protein expression by immunoblot analysis.

\section{SDS-PAGE and immunoblotting}

After $24 \mathrm{~h}$ incubation with APAP or DMSO, the cells were washed with a phosphate buffer, $\mathrm{pH} 7.5$, and the total protein fractions or immunoprecipitates were analysed with SDS-PAGE using $7.5 \%$ or $10 \%$ gels. For immunoblotting, gels were transferred to nitrocellulose membranes. The first antibodies, Alpi, GAPDH or TJP1, were diluted at 1:1000, 1:2000 or 1:500 and detected with a second antibody (anti-mouse or antirabbit IgG HRP-linked, 1:20000 diluted) and peroxidase reagent (cell signalling technology, New England Biolabs, Germany), using the imaging system Stella 3200 (raytest, Germany).

\section{Statistical Analysis}

Results are expressed as the means \pm standard error of the mean (S.E.M.) unless stated otherwise. Statistical differences between the two groups were assessed with the two-tailed unpaired t-test by GraphPad Prism software. The significance level was set at alpha $=5 \%(p=0.05)$ for all comparisons.

\section{Results}

The differentiated Caco-2 barrier model was useful for assessing new APAP effects on intestinal membrane properties [24, 25].

Dose-dependent effect of APAP on cytotoxicity

First, we assessed the cytotoxicity of APAP using an endpoint assay after $24 \mathrm{~h}$. No significant LDH release from Caco- 2 cells was detected after the Caco-2 cells were treated with $10 \mathrm{mM}$ APAP or vehicle (0.55\% DMSO) compared to the control (untreated) (Fig. 1A). 


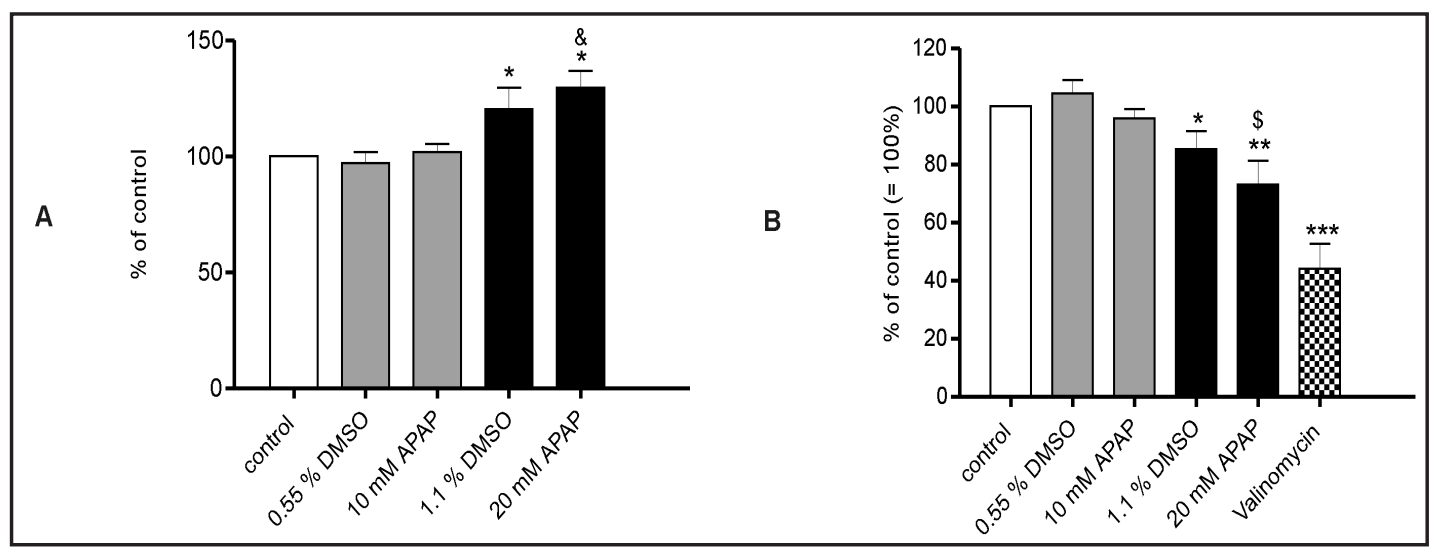

Fig. 1. Dose-dependent effect of APAP on cytotoxicity (LDH assay) and on mitochondrial membrane potential (JC-1 assay). The 21 days differentiated Caco- 2 cells were incubated with $0.55 \%, 1.1 \%$ DMSO and 10, 20 mM APAP for $24 \mathrm{~h}$. A) The LDH release in the supernatant was measured by the LDH assay. S.E.M. $\pm 8-18$. ${ }^{*} \mathrm{p}<0.005$ vs. control (untreated cells) and $\& \mathrm{p}<0.005$ vs. $10 \mathrm{mM}$ APAP. B) Mitochondrial membrane potential $\Delta \Psi \mathrm{m}$ was measured by JC-1 assay. The ratio of red fluorescence (J-aggregates) to the green fluorescence (J-monomers) of the control (untreated cells) was set to $100 \%$. Valinomycin was used as a positive control for the JC-1 assay. S.E.M. $\pm 3-4 .{ }^{*} \mathrm{p}<0.05$ and ${ }^{* *} \mathrm{p}<0.005$ and ${ }^{* * *} \mathrm{p}<0.001$ vs. control (untreated cells), $\$ \mathrm{p}<0.05$ vs. $10 \mathrm{mM}$ APAP.

Fig. 2. Transport of APAP from the apical to the basolateral side. APAP concentration on the basolateral side was measured by HPLC analysis after 4 h, 6 h, 24 h treatment with APAP (0-20 mM) on the apical side. S.E.M. \pm 2 .

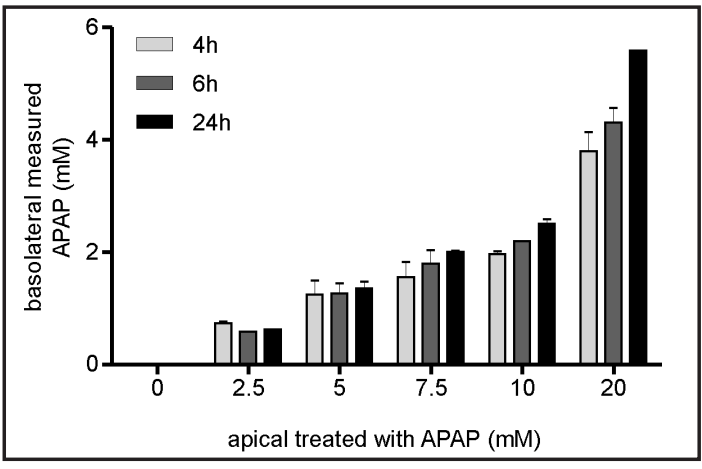

LDH release increased significantly, with 29\% in Caco-2 cells treated for 24 h with $20 \mathrm{mM}$ APAP, but there was also an increase of $12 \%$ in the corresponding vehicle control $11.1 \%$ DMSO) (Fig. 1A). Therefore, the dose range of APAP from 0-10 mM until 24 h shows no cytotoxic effect and should have been rational for the following in vitro studies with the differentiated Caco-2 barrier model.

\section{Dose-dependent effect of APAP on mitochondrial membrane potential ( $\triangle \Psi \mathrm{m})$}

Mitochondrial dysfunction is an early toxic event in liver cells in response to toxic APAP doses, and this is one of the earliest events to occur in the induction of apoptosis [31]. In general, it occurs before the plasma membrane leakage for LDH. $10 \mathrm{mM}$ APAP, and its corresponding vehicle control $(0.55 \%$ DMSO) did not significantly decrease the mitochondrial membrane potential $(\Delta \Psi \mathrm{m})$ compared to the control (untreated) (Fig. 1B). Caco-2 cells treated with $20 \mathrm{mM}$ APAP led to a significant decrease of $27 \%$ when compared to the untreated control which was set as $100 \%$ and about $15 \%$ in its corresponding vehicle control (Fig.1B). Valinomycin treated Caco-2 cells were taken as a positive control, and their mitochondrial membrane potential decreased significantly by $56 \%$.

Changes in APAP flux

The flux of APAP from the apical to the basolateral side increased in a time- and dosedependent manner (Fig. 2). For this experiment, 0-20 mM APAP was added on the apical side, 


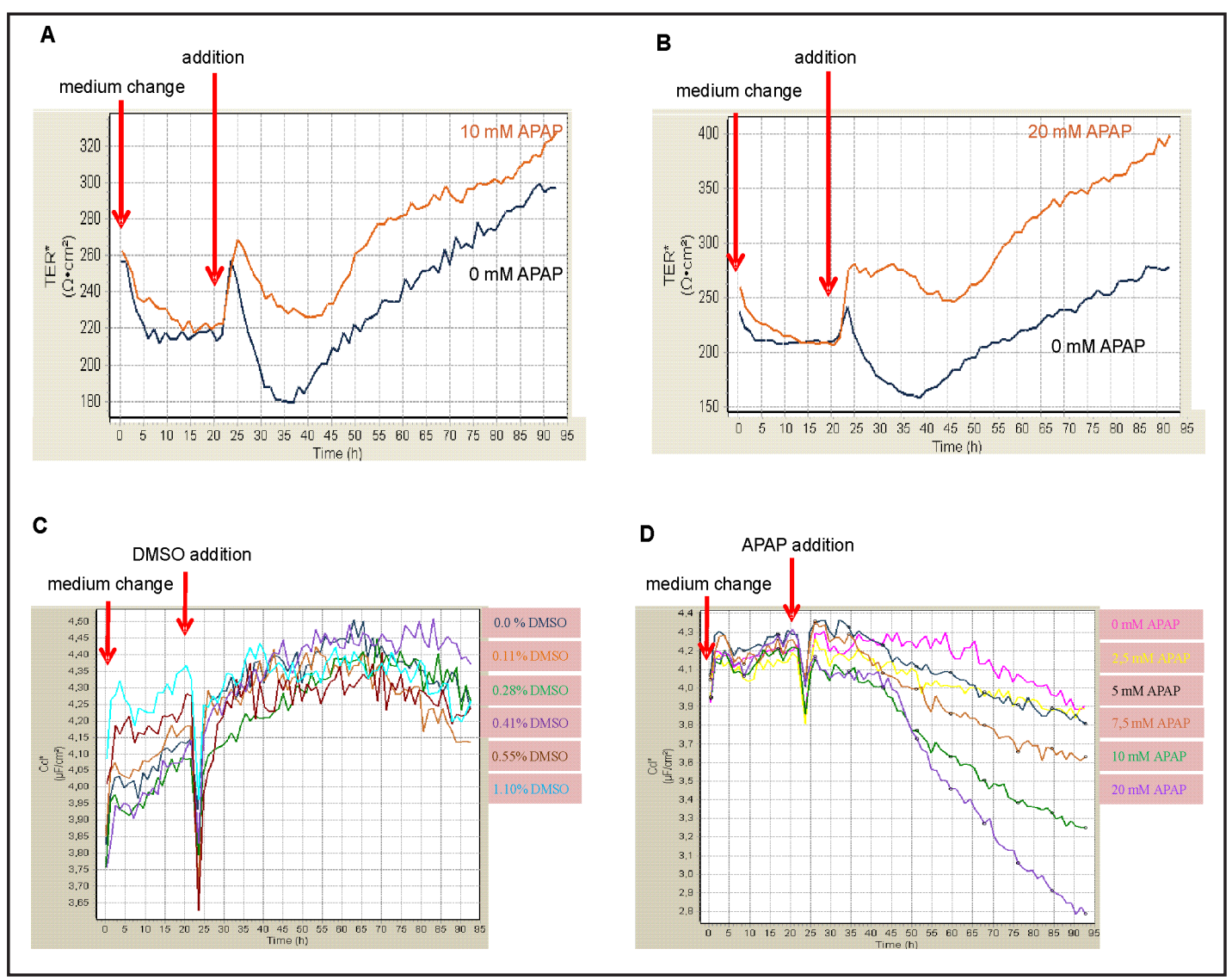

Fig. 3. Impedance monitoring of dose-dependent APAP and its vehicles (DMSO) of the TER value and of the cell capacitance (Ccl) of Caco-2 barrier model using cellZscope system. Effect of $10 \mathrm{mM}(\mathrm{A})$, and $20 \mathrm{mM}(\mathrm{B})$ APAP and its corresponding vehicle (DMSO) on the TER value. (C) Dose-dependency of the effect of DMSO application and D) of APAP application on cell capacitance. The results of impedance monitoring from one out of two experiments is shown.

and after $24 \mathrm{~h}$ APAP concentrations were determined basolaterally using HPLC analysis. The flux of APAP from the apical to the basolateral side increased slightly in a dose dependent manner after $24 \mathrm{~h}$ incubation time, after application of $0,5,7.5,10 \mathrm{mM}$ APAP on the apical side (Fig. 2). The concentration dependent permeability kinetic confirmed that the APAP transport through the Caco-2 cell barrier was passive.

The barrier properties of differentiated Caco-2 cells were monitored using impedance spectroscopy prior to and during the incubation time with APAP (Fig. 3). Both $10 \mathrm{mM}$ and $20 \mathrm{mM}$ APAP increased the TER values (Fig. 3A, 3B). The baseline TER values prior to APAP or to the corresponding vehicle (DMSO $=0 \mathrm{mM}$ APAP) addition were around 230-260 $\mathrm{Ohm}$ $\mathrm{x} \mathrm{cm}^{2}$. After the addition of vehicle $(0.55 \%, 1.1 \%$ DMSO) or APAP $(10 \mathrm{mM}, 20 \mathrm{mM})$, TER values quickly increased and dropped down again after a few hours, but the ratio of TER values in the APAP treated cells as opposed to vehicle treated cells were almost all higher over time. $20 \mathrm{mM}$ APAP led to a further increase of the TER value $\left(400 \mathrm{Ohm} \mathrm{x} \mathrm{cm}{ }^{2}\right)$ of about $18 \%$ after $72 \mathrm{~h}$, compared to $10 \mathrm{mM}$ APAP treated cells (330 $\left.\mathrm{Ohm} \mathrm{x} \mathrm{cm}^{2}\right)$. Compared to the corresponding vehicle controls ( $0 \mathrm{mM}$ APAP), there was a TER value increase of $9 \%$ in 10 mM APAP and 35\% in 20 mM APAP treated Caco-2 barrier models (Fig. 3A, 3B). Both TER measurements using different systems have shown that APAP caused an increase of the TER value, and this could be due to the increase of the membrane integrity in the differentiated Caco-2 barrier model. 


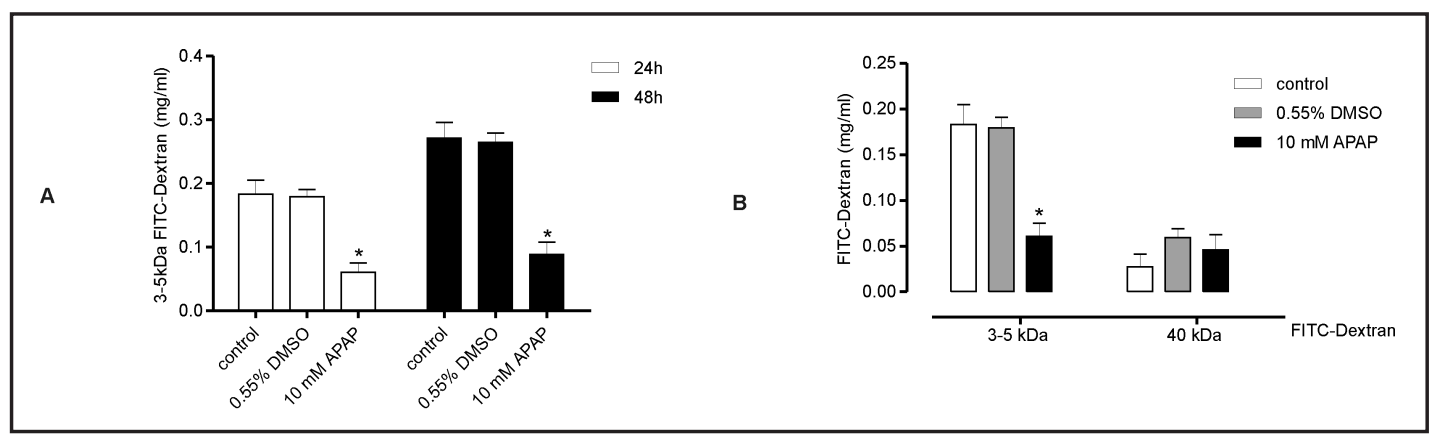

Fig. 4. Permeability to FITC-dextran molecules. (A) APAP effect on permeability to small FITC-dextran (3-5 kDa). (B) Comparison between permeability to small and large FITC-dextran molecules. S.E.M. $\pm 3 .{ }^{*} \mathrm{p}<0.05$ vs. control.

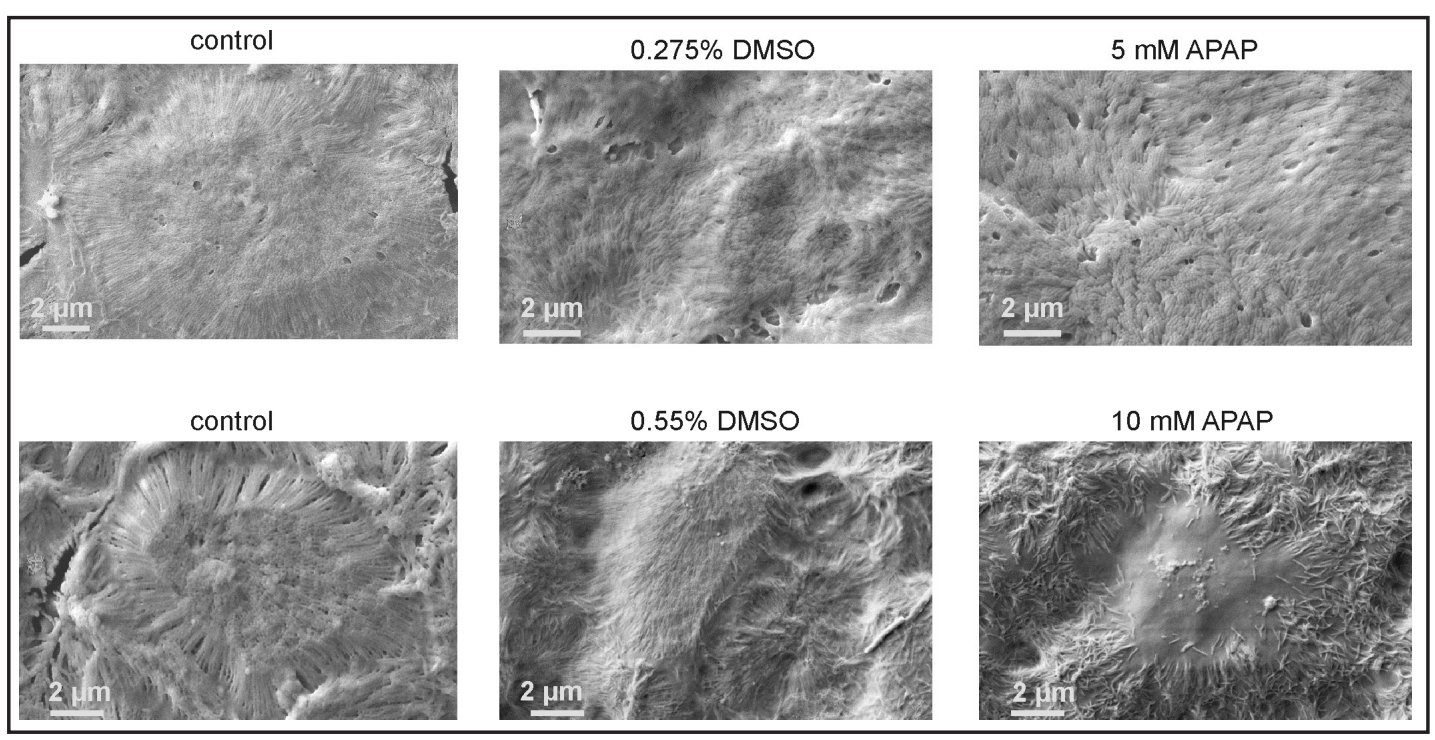

Fig. 5. Effect of APAP on cell surface topography and microvilli using SEM. Figures 5A and 5B show a view of the sample with SE2 detector. Images one out of three experiments are shown.

\section{APAP decreases the cell capacitance (Ccl) as a function of dose}

Using impedance spectroscopy, we recorded that APAP dose-dependently decreased the cell capacitance, but in the corresponding vehicle (0.55\% DMSO), it remained roughly unchanged (Fig. 3C, 3D). In the Caco-2 barrier models, cell capacitance began to drop down after APAP treatment (Fig. 3D). After $72 \mathrm{~h}$ treatment with $20 \mathrm{mM}$ APAP, cell capacitance declined at $29 \%\left(\mathrm{Ccl}\right.$ at $2.8 \mu \mathrm{F} / \mathrm{cm}^{2}$ ) compared to $0 \mathrm{mM} \mathrm{APAP}\left(\mathrm{Ccl}\right.$ at $3.93 \mu \mathrm{F} / \mathrm{cm}^{2}$ set as $100 \%$ ). In the DMSO controls, cell capacitance did not change significantly (Fig. 3C).

\section{APAP reduces permeability to small molecule}

Changes in TER indicate alterations in epithelial barrier function or in the transcellular permeability of ions [32]. The physiological significance of the TER increase in the Caco-2 barrier model was elucidated, while we tested whether APAP also impacts cell permeability. We first studied the effects of APAP on permeability to the FITC-dextran. Apical pretreatment with $10 \mathrm{mM}$ APAP caused significantly less membrane permeability to 3-5 kDa FITC-dextran from the apical to the basolateral compartment over time $(24 \mathrm{~h}, 48 \mathrm{~h})$ compared to the vehicle $(0.55 \%$ DMSO) or control (untreated) (Fig. 4A). For instance, after $24 \mathrm{~h}$ in $10 \mathrm{mM}$ for the pretreated Caco-2 barrier models, there was a $66 \%$ reduced permeability to $3-5 \mathrm{kDa}$ FITC-dextran compared to the vehicle or control (Fig. 4A). This experiment demonstrated the reduced permeability in the Caco 2 barrier model for small FITC-dextran (3-5 kDa) in 
Fig. 6. The effect of APAP on intestinal alkaline phosphatase (Alpi). The ratio of Alpi to GAPDH antibody protein expression was calculated and set at 1 -fold in untreated cells. S.E.M. \pm 3 .

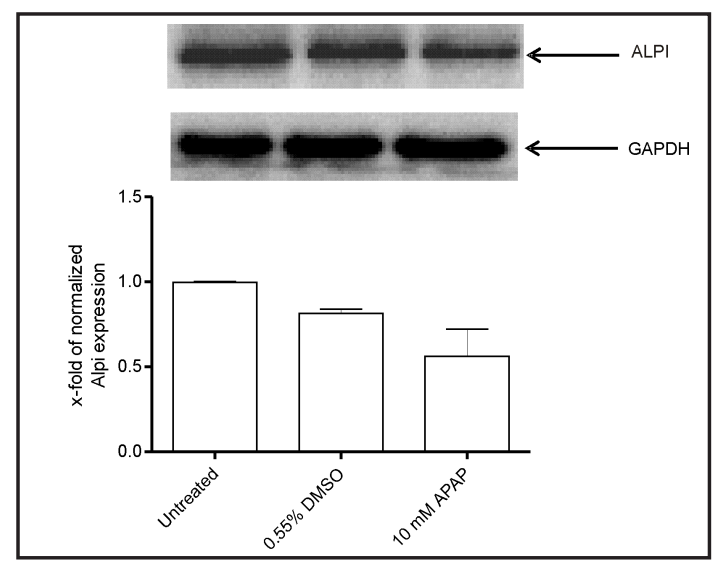

response to APAP treatment. However, the large FITC-dextran (40 kDa) was first detectable in the basolateral compartment after $48 \mathrm{~h}$. The permeability from the apical to the basolateral compartment stayed roughly unchanged in comparison to the control and vehicle (Fig. 4B). The application of $10 \mathrm{mM}$ APAP impaired the paracellular transport of small FITC-dextran molecules significantly over time. Large FITC-dextran could not pass paracellularly.

APAP changes the cell surface topography and decreases the number of microvilli and expression of microvilli marker protein intestinal alkaline phosphatase (Alpi)

Recently, we recorded a possible impact of the APAP effect on cell membrane topography using AFM [18]. To validate this data on the cell surface and show the effect of APAP on the number of microvilli, we have used SEM. Characteristic cellular surface profiles of APAP treated Caco-2 cells in the barrier model which were then compared to the DMSO controls (Fig. 5A, 5B).

Ultrastructural analysis of the apical cell surfaces in the Caco-2 barrier model using SEM revealed that the number of microvilli on the apical Caco- 2 cell surfaces was significantly reduced after a $24 \mathrm{~h}$ incubation period, with $10 \mathrm{mM}$ APAP but not with $5 \mathrm{mM}$ APAP compared to the corresponding vehicle control $(0,275 \%$ DMSO, 0.55\% DMSO) (Fig. 5A, 5B). In detail, APAP treatment in differentiated Caco- 2 cells led to loss of microvilli at their central apical cell area, and instead a large cytoplasma-facing area was detectable. Small cell protrusions were visible in the centre of the apical surface of the cells. The microvilli near the cell borders which surrounded the microvilli-free zone were of lower density compared to the vehicle control. The whole surface of the corresponding vehicle control was densely covered with small microvilli (brush border), and cytoplasma-facing surfaces were hardly detectable (Fig. 5B). To validate the reduction of the number of microvilli after the APAP treatment, the expression of intestinal alkaline phosphatase (Alpi) which is marker of microvilli membrane was tested by western blot analysis [21,33]. We have shown that a $10 \mathrm{mM}$ APAP treatment decreases the protein expression of Alpi in differentiated Caco-2 cells (Fig. 6).

\section{APAP increases efflux of Rh123 from basolateral to the apical side}

Rh123 was used as substrate and tracer in the MDR1 transporter activity assay [28]. The efflux of Rh123 from the basolateral to the apical compartment increased time- and dose-dependently, indicating that the MDR1 transporter was active in the Caco-2 barrier models (Fig. 7A). APAP dose-dependently increased the Rh123 efflux rate to a higher extent than the corresponding vehicle. In the untreated controls, the Rh123 efflux was lower than in the vehicle controls. The changes in Rh123 efflux indicate that MDR1 activity also increased time- and dose-dependently in the vehicle controls, but to a lower extent than in the corresponding APAP treated Caco-2 barrier models (Fig. 7A).

APAP increases its own efflux from the basolateral to the apical side

In addition, we investigated whether APAP is able to influence its own efflux, using HPLC (Fig. 7B). After basolateral treatment with a high APAP dose (10 mM) (set as 100\%), 


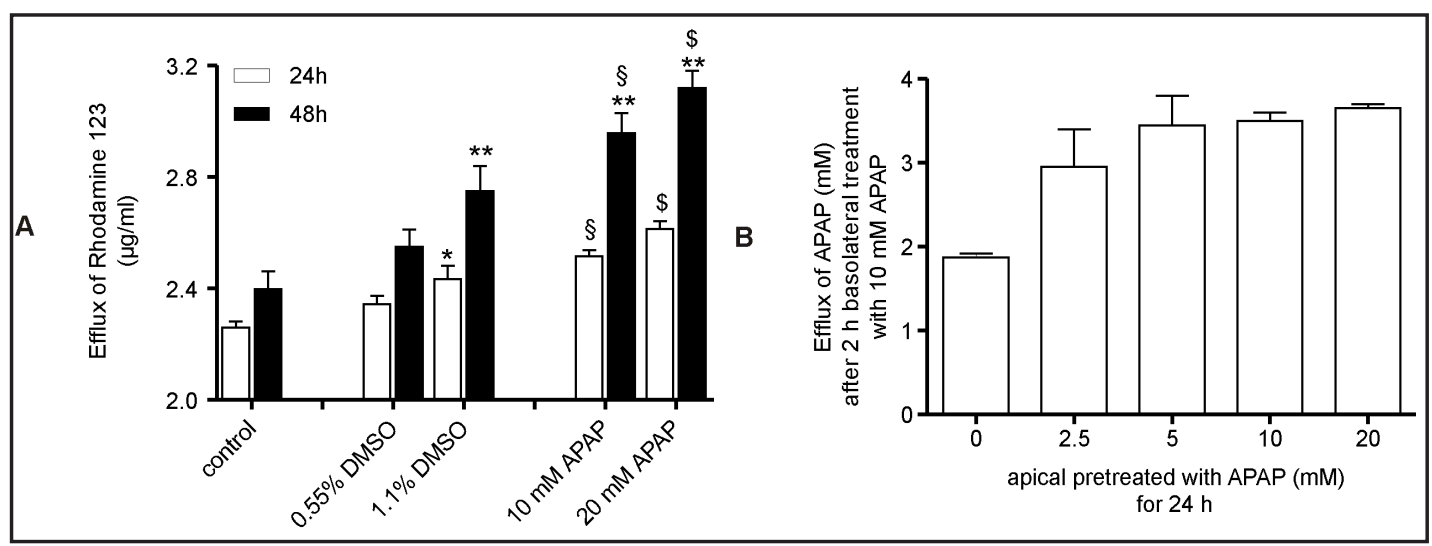

Fig. 7. A) The effect of APAP and its vehicle on MDR 1 activity. The transport activity of Rh123 from the basolateral to the apical side was measured fluorometrically after $24 \mathrm{~h}$ or $48 \mathrm{~h}$ incubation time. S.E.M. \pm 4 . ${ }^{*} \mathrm{p}<0.05$ and ${ }^{* *} \mathrm{p}<0.005$ vs. control (untreated cells), $\$ \mathrm{p}<0.005$ vs. $0.55 \%$ DMSO and $\$ \mathrm{p}<0.05$ vs. $1.1 \%$ DMSO. B) Measurement of APAP concentration after transport from the basolateral to the apical side, after $24 \mathrm{~h}$ apical pretreatment with APAP. The differentiated Caco- 2 cells were apically pretreated with different concentrations of $\operatorname{APAP}(0,2.5,5,10,20 \mathrm{mM})$ for $24 \mathrm{~h}$. After that, the APAP medium was removed and replaced with $10 \mathrm{mM}$ APAP on the basolateral side for $2 \mathrm{~h}$. The concentration of transported APAP from the basolateral side to the apical side was determined using HPLC analysis. S.E.M. \pm 4 .

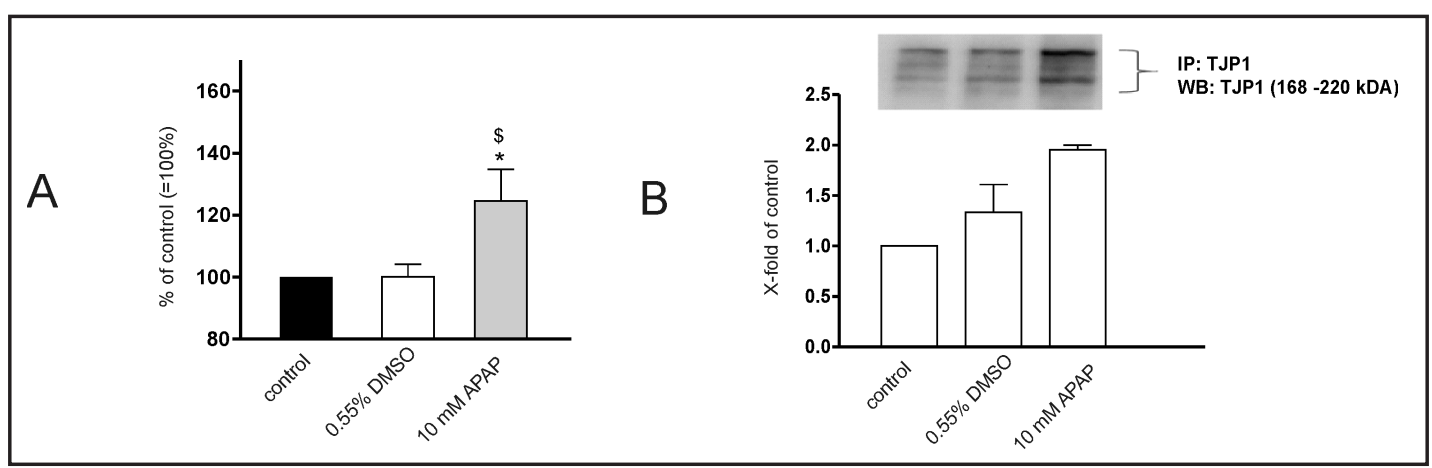

Fig. 8. A) Effect of APAP and its vehicle on the TER value and B) TJP1 protein expression. After $24 \mathrm{~h}$ treatment with APAP and its vehicle, the TER value was measured and proteins were then extracted. TJP1 proteins were immunoprecipitated and immunoblotted. An image from one out of three experiments is shown.* $\mathrm{p}<0.05$ control vs. $0.05, \$ \mathrm{p}<0.05$ vs.DMSO. S.E.M. $\pm 6-10$.

$1.9 \mathrm{mM}$ parent APAP was transported to the apical side after $2 \mathrm{~h}$. Apical pretreatment with $2.5 \mathrm{mM}$ APAP for $24 \mathrm{~h}$ led to an increase in APAP efflux to $3 \mathrm{mM}$. An apical pretreatment with $5 \mathrm{mM}$ APAP increases the concentration of exported APAP. For higher APAP concentrations, nearly constant basolateral APAP levels of $3.5 \mathrm{mM}$ are reached (Fig. 7B). This indicates that efflux transporters are responsible for the APAP efflux from basolateral to the apical side that reached saturability when pretreated with an apical concentration of $5 \mathrm{mM}$ APAP or higher values for $24 \mathrm{~h}$.

\section{APAP increases protein expression of tight junction protein-1 (TJP1)}

We analysed the immunoprecipitation of TJP1 from extracts after $24 \mathrm{~h}$ of APAP treatment. In APAP treated cells, the TJP1 protein expression increased about 2-fold in comparison to the untreated cells and 1.5-fold in its vehicle (Fig. 8A).

\section{APAP increases TER value}

To investigate whether APAP induced TJP1 protein expression is in accordance with the TER value, we measured the TER value via the electrical resistance produced by the tight 
cell monolayer. TER values increased after $24 \mathrm{~h}$ incubation time at $10 \mathrm{mM}$ compared to the control (untreated set as 100\%). In fact, the increasing of TER values is in accordance with the increasing of TJP1 protein expression (Fig. 8B).

\section{Discussion}

The in vitro APAP effects on the intestinal membrane properties lead to the assumption that polarized intestinal epithelial cells are involved in gut adaptation and/or defence strategies against APAP.

\section{APAP effects on intestine}

Research on APAP in the past focused mainly on the investigation of compensatory changes in the liver, because the intake of high doses of APAP can cause hepatotoxicity [34]. APAP toxicity is the foremost cause of acute liver failure in the Western World [35]. To our knowledge, only few APAP studies exist concerning the intestine. This might be due to the quick and complete absorption of APAP into the intestine [8], indicating the presumably insignificant regulating function of the intestinal epithelial barrier. Furthermore, APAP side effects on the intestinal barrier properties have not been investigated extensively, because the higher complexity of in vivo versus in vitro situations, makes it difficult to discriminate and analyse the intestinal APAP effects per se in clinical studies. Drug absorption in vivo depends on additional parameters like the more complex small intestinal mucosa, the cryptvillus-axis, the unstirred water layer, the rate of gastric emptying, and composition and $\mathrm{pH}$ value of the gastrointestinal fluids and solids. Moreover, APAP in therapeutic dose is not associated with increased gastrointestinal toxicity and remains widely unobtrusive on the bowel, as shown in clinical trials [4-7]. In toxic dose, the hepatotoxic effects of APAP are more prominent than its intestinal effects.

\section{Actions of APAP versus NSAIDs on the intestinal epithelium}

APAP is structurally related to non-steroidal anti-inflammatory drugs (NSAIDs), but acts partly different. APAP as pain and fever reducer is preferred over NSAIDs in some patients because it carries a lower risk of gastrointestinal toxicity and may be better tolerated than NSAIDs [36]. Indeed, chronic users of NSAIDs have a markedly higher risk of bleeding and visible damage to their small intestine $[37,38]$. But unlike typical NSAIDs (ibuprofen, naproxen, indomethacin), APAP has only minor inhibitory effects on cyclooxygenase activity (Cox-1 and Cox-2) -the existence of Cox-3 is debated- that reduces the levels of protective prostaglandins involved in fever, pain and inflammation [39]. Analgesia is very likely produced by the target transient receptor potential ankyrin 1 (TRPA1), a protein located on the surface of nerve cells [39]. An important concern about several NSAIDs is their "topical" effect on the small intestinal epithelium that can lead to mitochondrial damage and finally to mucosal injury [40].

The more acidic NSAIDs may directly irritate the intestinal mucosa. However, the notable contrast to APAP, is, that in vivo administered NSAIDs increase intestinal permeability within $12 \mathrm{~h}$ and $24 \mathrm{~h}$ and disrupt the intercellular junctions [38, 40]. In our study, a $10 \mathrm{mM}$ dose of APAP in $24 \mathrm{~h}$ has been shown to be non-toxic to the Caco-2 barrier model (Fig.1A, Fig. 1B). APAP reduced permeability and impaired the paracellular transport of small molecules FITC-dextrans significantly $(\mathrm{p}<0.05)$ over time (Fig. 4A). Large FITC-dextran could not pass paracellularly (Fig. 4B). Furthermore, TER (Fig. 3A, Fig. 8A) and protein expression of TJP1 (Fig. 8B) increased.

\section{APAP metabolism}

In the intestine, the majority of APAP metabolism in therapeutic use is by glucuronidation and sulphation. In overdose, clearance of APAP becomes saturated and its half-life may become prolonged to more than 4 hours. A prolonged half-life indicates that the conjugation 
pathways are saturated, and that an increasing proportion of APAP is being metabolised. In the Caco-2 barrier model, phase II metabolism and efflux activities are happening simultaneously. Siissalo et al. do not detect APAP glucuronide, but apical and basolateral effluxes of paracetamol sulphate [41]. In our study we investigate the parent compound and not its glucuronide and/or sulfate metabolites (Fig. 7B). Conjugation of APAP and effluxes of its metabolites might influence altered transporter expression and also the transporter activity (Fig. 7A, 7B).

\section{Low cytotoxicity of APAP on Caco-2 barrier model}

With doses lower than $10 \mathrm{mM}$ APAP, there was no LDH release and no breakdown of the mitochondrial membrane potential $\triangle \Psi$ m (Fig.1A, Fig. 1B). Thus, apically administered $10 \mathrm{mM}$ APAP should considered as non toxic dose in our Caco-2 barrier model. The usual adult minimal daily dose of APAP is $1 \mathrm{~g}$, which is equivalent to $4.4 \mathrm{mM}$ in our in vitro model. Intestinal volume was from the small intestinal volume to a value of $1.5 \mathrm{~L}$ ( $3 \mathrm{~m}$ length, 2.5 $\mathrm{cm}$ diameter)). The maximum in vivo daily dose is $4 \mathrm{~g}$, which is equivalent to $17.6 \mathrm{mM}$ in the in vitro model [2]. In our Caco-2 barrier model, apically administered $10 \mathrm{mM}$ APAP resulted in $2.5 \mathrm{mM}$ APAP on the basolateral side after $24 \mathrm{~h}$ (Fig. 2). This is considered a toxic dose for humans. The therapeutic APAP plasma levels after oral APAP ingestion in humans are 66-199 $\mu \mathrm{M}$ and toxic plasma levels are $>1324 \mu \mathrm{M}$ [42]. We consider apically administered $20 \mathrm{mM}$ APAP is a toxic dose to the Caco-2 barrier model, because it increased LDH release (Fig. 1A) and decreased $\triangle \Psi \mathrm{m}$ (Fig. 1B). The very low cytotoxicity at $10 \mathrm{mM}$ of APAP on the intestinal barrier model stands in opposition to the toxic APAP effects on liver cells under the same conditions. This may be intestinal-specific and due to adaptive regulations of the intestinal epithelial cells. For instance, the application of $10 \mathrm{mM}$ APAP led to an increased LDH release, oxidative stress, glutathione depletion, mitochondrial dysfunction and hepatotoxicity in HepaRG cells [3]. Hoftiezer et al. have found that intake of $650 \mathrm{mg} / \mathrm{meal}$ four times a day over two weeks does not cause markedly duodenal mucosal damage in healthy subjects [43]. This is similar to our results: with doses below $5 \mathrm{mM}$ APAP over $24 \mathrm{~h}$, there was no loss of microvilli (Fig. 5A).

\section{APAP effects on cell membrane properties}

We found several changes in Caco-2 cell membrane properties. TER measurements using two different systems revealed that APAP caused a dose- and time-dependent increase of TER values (Fig. 3, Fig. 8A). This increase in TER is indicative of the closing of junctions, mainly the tight junctions, located at the top apical portion between the epithelial cells. We found TJP1 protein overexpression in our treated samples as opposed to the vehicle control and the control (Fig. 8A). The critical components of the Caco-2 cell monolayer that account for TER are the epithelium itself, the paracellular space, the tight junction resistance, the intercellular space resistance and the apical and basolateral membrane resistance [44]. An increase in membrane integrity coincided with a decrease of small FITC-dextran permeability, indicating that APAP reduced paracellular transport (Fig. 4A, 4B). Large FITCdextran molecules did not pass trans- and paracellularly (Fig. 4B), thus indicating an intact functional barrier. The intact barrier was further validated by low LDH leakage through the Caco-2 plasma membranes (Fig. 1A). 10 mM APAP caused several changes in the Caco-2 cell membrane properties. There was a partial loss of microvilli at $10 \mathrm{mM}$ APAP (Fig. 5B), which can be explained by microvilli damage caused by the drug itself, or by reorganization of the intestinal epithelial cell membranes due to cytoskeleton dynamics. Both options need further evaluation. Interestingly, the partial loss of microvilli did not result in an increase in cytotoxicity (Fig. 5B, Fig. 1A). Clark et al. also demonstrated microvilli damage in Caco-2 cells in the absence of increased LDH release [45]. However, a topical and erosive effect of the neutral molecule on the microvilli of the small intestinal epithelium is rather unlikely because of its proven high gastrointestinal compatibility as opposed to the NSAID induced enteropathy [40]. We argue that the reduction in the number of microvilli on the apical Caco-2 cell surface is part of an adaptation process against high doses of APAP and that it 
may be protective to the intestinal cells because the absorption area is reduced. Microvilli elimination on intestinal epithelium may be one reason why humans can adapt to APAPinduced toxicity similar to rodents [12-14].

Furthermore, APAP dose-dependently decreased the cell capacitance (Fig. 3D). This cooccurred with a change in cell surface morphology, a reduced number of microvilli (Fig. 5B) and increased MDR1 activity (Fig. 7A), indicating the accompanied strong presence of MDR1 transport proteins in the Caco-2 plasma membrane. Recently, we used a distinct surface analysis method (Atomic force microscopy) and found that APAP affects cell membrane topography in the Caco-2 barrier model [18]. Similarly, changes in the surface morphology of mice hepatocytes in response to APAP have been reported [46], indicating a cell type unspecific drug effect, even though hepatocytes possess no brush border but microvilli on their cell surface.

The current view is that microvilli increase the absorptive surface area for the uptake of extracellular compounds [47]. The loss of microvilli may reduce the absorptive surface area and protect the intestinal cells, because passive transport via para- and transcellular diffusion of APAP is limited according to Fick's law [48]. To confirm the loss of microvilli, we used a typical intestinal brush border marker protein, Alpi [21]. The decrease of Alpi protein expression coincided with a reduction of the number of microvilli (Fig. 6, Fig. 5B).

To show how is the effect of APAP on the MDR1 activity, Rh123 - as a high-affinity substrate for MDR1 - was added to the basolateral side of the cells after $24 \mathrm{~h}$ APAP pretreatment. APAP dose-dependently increased the Rh123 efflux rate to a higher extent than the corresponding vehicle or the untreated controls (Fig. 7A). We conclude that APAP pretreatment significantly $(\mathrm{p}<0.05)$ increases MDR1 activity, and that the efflux of APAP (parent drug) and/or its metabolites was accelerated. Ghanem et al. report that APAP can induce MDR1 expression and activity in rat intestines and in the LS 174T human intestinal cell line [49].

When other MDR1 substrates are co-administered with APAP the net intestinal absorption of these drugs could be indirectly influenced. The change in pharmacokinetics and therapeutic efficacy of these drugs, may be clinically relevant [49]. In addition, in human livers, altered MDR expression has been described in APAP consumption toxicity [50] .

\section{Limited APAP elimination due to efflux transporter saturation}

Another aspect of clinical relevance is the intestinal efflux transporter saturation in APAP high-dosed or overdosed patients. Efflux transporter saturation can limit the elimination of APAP itself or of subsequently administered compounds, such as drugs or nutrients [49]. Transepithelial transport of APAP has been investigated in intact rabbit intestinal tissues using Ussing chambers [51]. In jejunum, ileum and distal colon, both unidirectional fluxes of APAP were unsaturable over the concentration range from 0.1 to $30 \mathrm{mM}$. However, we demonstrated that APAP is able to influence its intestinal efflux in vitro (Fig. 7B). High dosage APAP pretreatment on the apical (luminal) side for $24 \mathrm{~h}$ leads to saturated efflux of APAP to the basolateral (plasma) side. The saturability indicates that transport proteins such as MDR1 (Fig. 7A) are involved in the APAP efflux. When transport proteins are saturated, accumulation and/or metabolism of APAP in intestinal epithelial cells and/or removal back to the luminal side can occur. As a result, a prolonged half-life of APAP is in the body and/or the increase of toxic metabolites in the gut that causes intestinal damage.

\section{Role of transporters in response to APAP}

Alterations in transporter expression followed by changes in transporter activity may also play a compensatory role in reducing the accumulation of potentially toxic compounds in Caco-2 cells. In a systems biology study, 13 ATP-binding cassette (ABC) and 115 Solute carrier (SLC) transporter genes were overexpressed in Caco-2 cells $30 \mathrm{~min}$ after APAP exposure [52]. Among these upregulated genes are transport proteins that may play a protective and/or detoxification role in Caco-2 response to APAP. For instance, members of the Multidrug Resistance-associated Protein (MRP) subfamily that are involved in multi- 


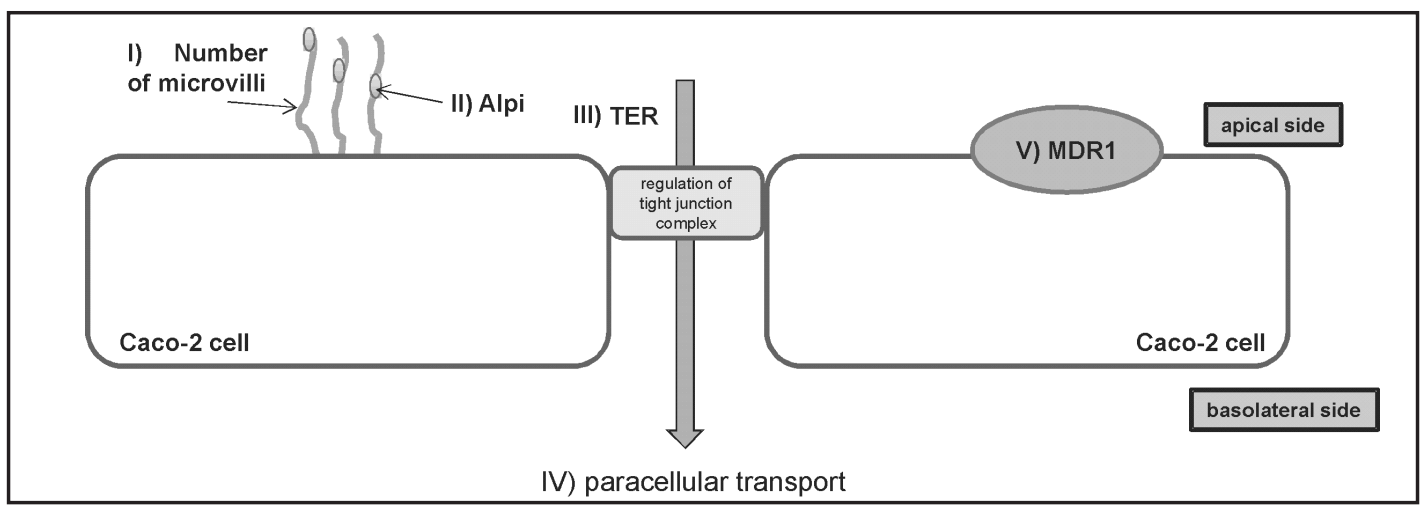

Fig. 9. Scheme of APAP changed membrane properties of Caco-2 barrier model. The scheme illustrates that APAP modulates cell membrane properties in the Caco-2 barrier model in various ways: I) reduction of the number of microvilli and II) Alpi expression, III) increase of membrane integrity (TER value), IV) decrease of permeability to small molecules (3-5 kDa FITC-Dextran), and V) enhancement of MDR1 activity (efflux of Rh123) and APAP efflux.

drug resistance, such as MRP9 and MRP6, were upregulated [52]. In addition, expression of S-adenosylmethionine carrier (SAMC) increased. SAMC is a mitochondrial carrier that catalyzes the transportation of S-adenosylmetionine from the cytosol to its place of action within the mitochondrium in exchange for internal substrates. S-adenosylmetionine is essential for mitochondrial metabolism - especially protein synthesis - and has a role in mitochondrial protection $[52,53]$. Upregulation of SAMC may be involved in keeping the mitochondrial membrane potential at high levels (Fig. 1B) and cytotoxicity low (Fig. 1A) in the $10 \mathrm{mM}$ APAP treated Caco-2 barrier models. In addition, two hepatic biomarkers (ABCC13 and ABCB4) were overexpressed upon exposure of Caco-2 cells to APAP reflecting the liver toxicity of APAP [52].

\section{Vehicle effect}

DMSO has been reported to induce MDR1 expression in colon carcinoma cell lines [54]. Caco-2 cells are also of colorectal origin [23], and in our study, the efflux of Rh123 increased time- and dose-dependently, but to a lower extent than in the corresponding APAP treated Caco-2 barrier models (Fig. 7A). For the in vitro experiments, DMSO was used as a biocompatible solvent for the poorly water-soluble APAP, but several cellular and pharmacological actions of DMSO have been described [55]. The ability of DMSO to protect cell membrane integrity is well documented [56]. Because of its effects on membrane penetration, membrane transport, and enhancement or reduction of effectiveness of other drugs, DMSO side effects and interactions with the APAP effects cannot be excluded. DMSO is known to be an effective hydroxyl scavenger and may act to neutralize the possible cytotoxic effects of APAP on the Caco-2 barrier model that are due to oxidative stress. In mice, the APAP-induced depletion of liver glutathione and hepatotoxicity was prevented when mice were pretreated with DMSO, although DMSO alone had no effect on liver glutathione levels [57].

\section{Summary}

Fig. 9 summarises APAP related changes of cell membrane properties across the Caco-2 barrier model that can cause a reduced net intestinal absorption: Altered Caco-2 cell surface morphology, a decreased number of microvilli and reduced Alpi expression, a reduced paracellular pathway (decrease of permeability to small molecules due to the raised membrane integrity (TER value), and enhancement of the efflux transporter activity, MDR1 (Fig. 7A). Furthermore, the comparison of the physical effects monitored by impedance spectroscopy as a non-invasive system for real-time monitoring along with the biologic 
Schäfer et al.: Acetaminophen Affects Intestinal Cell Membrane Properties

alterations assayed by transporter studies might be a promising strategy to better understand the effects of subsequently administered substances on the net intestinal absorption.

\section{Conclusion}

Continued examination of the mechanism by which APAP affects the cellular junction protein, TJP1 that is important together with other proteins of the tight junction complexes for maintaining cell membrane integrity and how the paracellular pathway is regulated will shed light on the local APAP effects on the intestinal barrier. The Caco-2 barrier model may be helpful together with further analysis of the gut and clinical studies to optimize therapeutic implications in cases of high dose APAP treatment against pain and fever and of consciously and unconsciously APAP overdose.

\section{Abbreviations}

Alpi (intestinal alkaline phosphatase); APAP (Acetaminophen or N-acetyl-paminophenol or Paracetamol); AFM (Atom force microscopy); DMSO (Dimethyl sulfoxide); FITC-dextran (Fluorescein isothiocyanate-dextran), HPLC (High-performance liquid chromatography); JC-1 (5,5',6,6'-tetrachloro-1,1',3,3'-tetraethylbenzimidazolylcarbocya nine iodide); LDH (Lactate dehydrogenase); IS (Impedance Spectroscopy); MDR1 (Multi Drug Resistance protein 1); Pgp (p-glycoprotein); Rh123 (Rhodamine 123); SEM (Scanning electron microscopy); TER (Transepithelial Electrical Resistance); TJ (Tight Junction); TJP1 (tight junction protein 1).

\section{Acknowledgements}

This work was supported by the state of Upper Austria. The SEM analysis done at JKU was supported by the Austrian Forschungsförderungsgesellschaft $\mathrm{GmbH}$ research program, under the project number 823398, the Federal Ministry of Economy, Family, Youth and the National Foundation for Research, Technology and Development (Austria), and voestalpine Stahl GmbH of Linz in Austria.

\section{References}

1 Larson AM: Acetaminophen hepatotoxicity. Clin Liver Dis 2007;11:525-48, vi.

2 http://www.drugs.com/acetaminophen.html. Acetaminophen Dosage. 2011.

- 3 Jaeschke H, McGill MR, Ramachandran A: Oxidant stress, mitochondria, and cell death mechanisms in drug-induced liver injury: lessons learned from acetaminophen hepatotoxicity. Drug Metab Rev 2012;44:88-106.

-4 Lanza FL, Codispoti JR, Nelson EB: An endoscopic comparison of gastroduodenal injury with over-thecounter doses of ketoprofen and acetaminophen. Am J Gastroenterol 1998;93:1051-1054.

5 Jerussi TP, Caubet JF, McCray JE, Handley DA: Clinical endoscopic evaluation of the gastroduodenal tolerance to (R)- ketoprofen, (R)- flurbiprofen, racemic ketoprofen, and paracetamol: a randomized, singleblind, placebo-controlled trial. J Clin Pharmacol 1998;38:19S-24S.

-6 Klotz U: Paracetamol (acetaminophen) - a popular and widely used nonopioid analgesic. Arzneimittelforschung 2012;62:355-359.

7 Rahme E, Barkun A, Nedjar H, Gaugris S, Watson D: Hospitalizations for upper and lower GI events associated with traditional NSAIDs and acetaminophen among the elderly in Quebec, Canada. Am J Gastroenterol 2008;103:872-882.

-8 Lu HH, Thomas JD, Tukker JJ, Fleisher D: Intestinal water and solute absorption studies: comparison of in situ perfusion with chronic isolated loops in rats. Pharm Res 1992;9:894-900. 
Schäfer et al.: Acetaminophen Affects Intestinal Cell Membrane Properties

9 Heading RC, Nimmo J, Prescott LF, Tothill P: The dependence of paracetamol absorption on the rate of gastric emptying. Br J Pharmacol 1973;47:415-421.

10 Schiodt FV, Ott P, Christensen E, Bondesen S: The value of plasma acetaminophen half-life in antidotetreated acetaminophen overdosage. Clin Pharmacol Ther 2002;71:221-225.

11 Brok J, Buckley N, Gluud C: Interventions for paracetamol (acetaminophen) overdose. Cochrane Database Syst Rev 2006;CD003328.

12 Shayiq RM, Roberts DW, Rothstein K, Snawder JE, Benson W, Ma X, Black M: Repeat exposure to incremental doses of acetaminophen provides protection against acetaminophen-induced lethality in mice: an explanation for high acetaminophen dosage in humans without hepatic injury. Hepatology 1999;29:451-463.

13 Watkins PB, Kaplowitz N, Slattery JT, Colonese CR, Colucci SV, Stewart PW, Harris SC: Aminotransferase elevations in healthy adults receiving 4 grams of acetaminophen daily: a randomized controlled trial. JAMA 2006;296:87-93.

14 Aleksunes LM, Campion SN, Goedken MJ, Manautou JE: Acquired resistance to acetaminophen hepatotoxicity is associated with induction of multidrug resistance-associated protein 4 (Mrp4) in proliferating hepatocytes. Toxicol Sci 2008;104:261-273.

-15 Ayrton A, Morgan P: Role of transport proteins in drug absorption, distribution and excretion. Xenobiotica 2001;31:469-497.

16 Takano M, Yumoto R, Murakami T: Expression and function of efflux drug transporters in the intestine. Pharmacol Ther 2006;109:137-161.

17 Harhaj NS, Antonetti DA: Regulation of tight junctions and loss of barrier function in pathophysiology. Int J Biochem Cell Biol 2004;36:1206-1237.

18 Lornejad-Schäfer MR, Schäfer C, Riethmueller C, Schroeder KR: Reduced bioavaibility of acetaminophen and of co-administerd substances across an intestinal barrier model through different mechanisms. Acta Physiologica 2012;204:134.

19 Brown JW, McKnight CJ: Molecular model of the microvillar cytoskeleton and organization of the brush border. PLoS One 2010;5:e9406.

20 Lange K: Fundamental role of microvilli in the main functions of differentiated cells: Outline of an universal regulating and signaling system at the cell periphery. J Cell Physiol 2011;226:896-927.

-21 Yang Y, Wandler AM, Postlethwait JH, Guillemin K: Dynamic Evolution of the LPS-Detoxifying Enzyme Intestinal Alkaline Phosphatase in Zebrafish and Other Vertebrates. Front Immunol 2012;3:314.

-22 Hunter J, Jepson MA, Tsuruo T, Simmons NL, Hirst BH: Functional expression of P-glycoprotein in apical membranes of human intestinal Caco-2 cells. Kinetics of vinblastine secretion and interaction with modulators. J Biol Chem 1993;268:14991-14997.

23 Hidalgo IJ, Raub TJ, Borchardt RT: Characterization of the human colon carcinoma cell line (Caco-2) as a model system for intestinal epithelial permeability. Gastroenterology 1989;96:736-749.

24 Artursson P: Epithelial transport of drugs in cell culture. I: A model for studying the passive diffusion of drugs over intestinal absorptive (Caco-2) cells. J Pharm Sci 1990;79:476-482.

-25 Hubatsch I, Ragnarsson EG, Artursson P: Determination of drug permeability and prediction of drug absorption in Caco-2 monolayers. Nat Protoc 2007;2:2111-2119.

26 Borchardt RT: Hidalgo, I.J., Raub, T. J., and Borchardt, R.T.: Characterization of the human colon carcinoma cell line (Caco-2) as a model system for intestinal epithelial permeability, Gastroenterology, 96, 736-749, 1989--the Backstory. AAPS J 2011;13:323-327.

27 Cossarizza A, Baccarani-Contri M, Kalashnikova G, Franceschi C: A new method for the cytofluorimetric analysis of mitochondrial membrane potential using the J-aggregate forming lipophilic cation 5,5',6,6'-tetrachloro-1,1',3,3'-tetraethylbenzimidazolcarbocyanine iodide (JC-1). Biochem Biophys Res Commun 1993;197:40-45.

28 Yumoto R, Murakami T, Nakamoto Y, Hasegawa R, Nagai J, Takano M: Transport of rhodamine 123, a P-glycoprotein substrate, across rat intestine and Caco-2 cell monolayers in the presence of cytochrome P-450 3A-related compounds. J Pharmacol Exp Ther 1999;289:149-155.

-29 Troutman MD, Thakker DR: Rhodamine 123 requires carrier-mediated influx for its activity as a P-glycoprotein substrate in Caco-2 cells. Pharm Res 2003;20:1192-1199.

30 Seth A, Sheth P, Elias BC, Rao R: Protein phosphatases 2A and 1 interact with occludin and negatively regulate the assembly of tight junctions in the CACO-2 cell monolayer. J Biol Chem 2007;282:11487-11498.

-31 Jaeschke H, Bajt ML: Intracellular signaling mechanisms of acetaminophen-induced liver cell death. Toxicol Sci 2006;89:31-41.

-32 Pinton P, Nougayrede JP, Del Rio JC, Moreno C, Marin DE, Ferrier L, Bracarense AP, Kolf-Clauw M, Oswald IP: The food contaminant deoxynivalenol, decreases intestinal barrier permeability and reduces claudin expression. Toxicol Appl Pharmacol 2009;237:41-48. 
Schäfer et al.: Acetaminophen Affects Intestinal Cell Membrane Properties

33 Mahmood S, Kaur K, Mittal N, Mahmood A: Giardia lamblia: expression of alkaline phosphatase activity in infected rat intestine. Exp Parasitol 2005;110:91-95.

-34 Bessems JG, Vermeulen NP: Paracetamol (acetaminophen)-induced toxicity: molecular and biochemical mechanisms, analogues and protective approaches. Crit Rev Toxicol 2001;31:55-138.

35 Khashab M, Tector AJ, Kwo PY: Epidemiology of acute liver failure. Curr Gastroenterol Rep 2007;9:66-73.

-36 Schilling A, Corey R, Leonard M, Eghtesad B: Acetaminophen: old drug, new warnings. Cleve Clin J Med 2010;77:19-27.

-37 Wallace JL: Mechanisms, prevention and clinical implications of nonsteroidal anti-inflammatory drugenteropathy. World J Gastroenterol 2013;19:1861-1876.

38 Park SC, Chun HJ, Kang CD, Sul D: Prevention and management of non-steroidal anti-inflammatory drugsinduced small intestinal injury. World J Gastroenterol 2011;17:4647-4653.

-39 Andersson DA, Gentry C, Alenmyr L, Killander D, Lewis SE, Andersson A, Bucher B, Galzi JL, Sterner O, Bevan S, Hogestatt ED, Zygmunt PM: TRPA1 mediates spinal antinociception induced by acetaminophen and the cannabinoid Delta(9)-tetrahydrocannabiorcol. Nat Commun 2011;2:551.

40 Somasundaram S, Rafi S, Hayllar J, Sigthorsson G, Jacob M, Price AB, Macpherson A, Mahmod T, Scott D, Wrigglesworth JM, Bjarnason I: Mitochondrial damage: a possible mechanism of the "topical" phase of NSAID induced injury to the rat intestine. Gut 1997;41:344-353.

41 Siissalo S, Laine L, Tolonen A, Kaukonen AM, Finel M, Hirvonen J: Caco-2 cell monolayers as a tool to study simultaneous phase II metabolism and metabolite efflux of indomethacin, paracetamol and 1-naphthol. Int J Pharm 2010;383:24-29.

42 Kratz A, Ferraro M, Sluss PM, Lewandrowski KB: Case records of the Massachusetts General Hospital. Weekly clinicopathological exercises. Laboratory reference values. N Engl J Med 2004;351:1548-1563.

43 Hoftiezer JW, O'Laughlin JC, Ivey KJ: Effects of 24 hours of aspirin, Bufferin, paracetamol and placebo on normal human gastroduodenal mucosa. Gut 1982;23:692-697.

44 Blikslager AT, Moeser AJ, Gookin JL, Jones SL, Odle J: Restoration of barrier function in injured intestinal mucosa. Physiol Rev 2007;87:545-564.

45 Clark KA, O’Driscoll C, Cooke CA, Smith BA, Wepasnick K, Fairbrother DH, Lees PS, Bressler JP: Evaluation of the interactions between multiwalled carbon nanotubes and Caco-2 cells. J Toxicol Environ Health A 2012;75:25-35.

-46 Walker RM, Racz WJ, McElligott TF: Scanning electron microscopic examination of acetaminophen-induced hepatotoxicity and congestion in mice. Am J Pathol 1983;113:321-330.

47 Schmidt RF, Lang F: Physiologie des Menschen: Mit Pathophysiologie. Springer Medizin Verlag, Heidelberg, 2007.

48 Thomas VH, Bhattachar S, Hitchingham L, Zocharski P, Naath M, Surendran N, Stoner CL, El-Kattan A: The road map to oral bioavailability: an industrial perspective. Expert Opin Drug Metab Toxicol 2006;2:591608.

49 Ghanem CI, Arias A, Novak A, Carpini GD, Villanueva S, Blazquez AG, Marin JJ, Mottino AD, Rubio MC: Acetaminophen-induced stimulation of MDR1 expression and activity in rat intestine and in LS 174T human intestinal cell line. Biochem Pharmacol 2011;81:244-250.

50 Barnes SN, Aleksunes LM, Augustine L, Scheffer GL, Goedken MJ, Jakowski AB, Pruimboom-Brees IM, Cherrington NJ, Manautou JE: Induction of hepatobiliary efflux transporters in acetaminophen-induced acute liver failure cases. Drug Metab Dispos 2007;35:1963-1969.

51 Swaan PW, Marks GJ, Ryan FM, Smith PL: Determination of transport rates for arginine and acetaminophen in rabbit intestinal tissues in vitro. Pharm Res 1994;11:283-287.

52 Khan S, Elshaer A, Rahman AS, Hanson P, Perrie Y, Mohammed AR: Systems biology approach to study permeability of paracetamol and its solid dispersion. Int J Pharm 2011;417:272-279.

53 Michael BJ, Ball JG, Wright MS, Van MS, Valentovic MA: Novel protective mechanisms for S-adenosyl-Lmethionine against acetaminophen hepatotoxicity: improvement of key antioxidant enzymatic function. Toxicol Lett 2012;212:320-328.

54 Mickley LA, Bates SE, Richert ND, Currier S, Tanaka S, Foss F, Rosen N, Fojo AT: Modulation of the expression of a multidrug resistance gene (mdr-1/P-glycoprotein) by differentiating agents. J Biol Chem 1989;264:18031-18040.

55 Santos NC, Figueira-Coelho J, Martins-Silva J, Saldanha C: Multidisciplinary utilization of dimethyl sulfoxide: pharmacological, cellular, and molecular aspects. Biochem Pharmacol 2003;65:1035-1041.

56 Sandborn EB, Stephens H, Bendayan M: The influence of dimethyl sulfoxide on cellular ultrastructure and cytochemistry. Ann N Y Acad Sci 1975;243:122-138.

57 Park Y, Smith RD, Combs AB, Kehrer JP: Prevention of acetaminophen-induced hepatotoxicity by dimethyl sulfoxide. Toxicology 1988;52:165-175. 